\title{
Development of control unit for smart power supply system using battery energy storages and residential PV-PCSs
}

\author{
Kiyotaka Fuji $^{\mathrm{a}, \mathrm{b}^{*}}$, Takahisa Kawagoe ${ }^{\mathrm{b}}$, Kenta Tanoue ${ }^{\mathrm{b}}$, Atsushi Shiota ${ }^{\mathrm{b}}$, Yasunori \\ Mitani $^{\mathrm{b}}$, Thongchart Kerdphol ${ }^{\mathrm{b}}$, Yaser Qudaih ${ }^{\mathrm{b}}$ \\ ${ }^{a}$ Department of Biological Functions and Engineering Graduate School of Life Science and Systems Engineering, Kyushu Institute \\ of Technology, Kitakyushu 808-0196, Japan \\ ${ }^{b}$ Department of Electrical and Electronic Engineering, Kyushu Institute of Technology, Kitakyushu 804-8550, Japan
}

\begin{abstract}
This research deals with the Non-Isolated Bidirectional Dc-Dc Converter (NBDC) control unit development for a smart power supply system using personal residential Photovoltaic-Power Conditioning Subsystem (PV-PCS), the results of circuits evaluation, and isolated PV-PCS operation connected battery storage (Electric vehicle storage etc.). The smart power supply system using the existing residential PCS with battery storage has an advantage that it can suppress the energy change during normal operation and can also construct the isolated power supply in an emergency case of power system cut-off. In PV power generation, PV power fluctuations caused by weather changes make the difficulty to obtain stable power output. Further, it can be expected that this adversely affects to the power system. By using this smart system control with an isolated power supply function, this battery storage can be provided the power for critical loads during the utility outage. In this paper, the comparison of voltage control mode in terms of battery voltage range is considered for the smart system operation. In particular, IGBT power semiconductor gate drive circuit of light insulation and current-voltage detection circuit with used photo-coupler of light insulation are newly developed for the smart power supply system operation. Moreover, the isolated power supplies effectiveness, the smart circuit development, and the experiment results of the PV-PCS interconnection isolated power system for stable supply with the existing residential PV-PCS of Japan are investigated, analyzed and discussed.
\end{abstract}

Keywords: Non-Isolated bidirectional dc-dc converter, battery storage, photovoltaic power generation, power conditioning subsystem, light insulation photo-coupler, electric vehicle

\section{Introduction}

Economic activity and energy consuming activities are inextricably linked. Thus, energy consumption is absolutely imperative in order to grow a certain economic. Currently, a primary energy is depended on a large part of fossil fuel resource. Thus, carbon dioxide $\left(\mathrm{CO}_{2}\right)$ that is emitted by combustion of the fossil fuel increases with the energy consumption has been increased. For this reason, the whole world is working towards to a low carbon society for reducing $\mathrm{CO}_{2}$ emissions as much as possible. By the influence of East Japan earthquake of March 2011 and a feed-in tariff for renewable energy of enforcement in July 2012, the introduction of photovoltaic power generation has been activated based on Japanese government's plan. On the other hand, it is attracting the attention to commercialize Electric Vehicles (EVs) in the automotive industry as activities toward a low-carbon society [1]-[6].

Photovoltaic (PV) power generation has a characteristic that the power output fluctuates severely depending on the weather conditions. Therefore, if a large amount PV generated power to the grid has been introduced, there is a risk of adverse effect on the stable power supply and power quality. Moreover, when the power system had been cut off by the disaster, it makes the difficulties to obtain stable power from

\footnotetext{
* Manuscript received April 15, 2015; revised August 12, 2015.

Corresponding author: Kiyotaka Fuji; Tel.: +81-90-5743-3431; E-mail address: fuji19690708@gmail.com.

doi: $10.12720 /$ sgce.4.3.159-168
} 
photovoltaic power generation in homes and facilities. In addition, because of nuclear power plants shut down, there is also a condition that power supply capacity has been tight depending on a season. However, in each home and each facility, if the power independence state can easily achieve from the power system, it is possible to adjust the flexible operation of "peak load reduction of the power system" or "power supply continuation of emergency power outage". Nevertheless, if the an electric vehicle can be used as a movable storage battery, power secure in power failure and fluctuation control and peak load reduction is expected by using the combination of the widely spread photovoltaic power generation to every household and facilities [7]-[9].

In this study, the system for coordinating the existing photovoltaic power generation systems and electric vehicle storage battery is proposed. Power supply system of the grid-connected system and independence system with a fluctuation suppression, peak load reduction and new functions of the power ensure in the power failure is constructed. Therefore, the development of Bidirectional dc-dc converter control circuit and control system is the main purpose as the coordinated control equipment of the photovoltaic power generation system and electric vehicle.

Bidirectional Dc-Dc Converters (BDC) has recently received a lot of attention due to the increasing need of systems with the capability of bidirectional energy transfer between two dc buses. Apart from traditional application in dc motor drives, the new applications of BDC have focused and included energy storages in renewable energy systems, fuel cell energy systems, Hybrid Electric Vehicles (HEV) and Uninterruptible Power Supplies (UPS). The fluctuated nature of most renewable energy resources, like wind and solar, makes them unsuitable for standalone operation as the sole source of power. A common solution to overcome this problem is to use an energy storage device besides the renewable energy resource in order to compensate these fluctuations and maintain a smooth and continuous power flow to the loads. As the most common and economical energy storage devices in medium-power range are batteries and super-capacitors, a dc-dc converter is always required energy exchange between storage device and the rest of system. Such a converter must have the bidirectional power flow capability with flexible control in all operating modes. For example, in HEV applications, BDCs are required to link different dc voltage buses and transfer energy between them. Besides, a BDC is used to exchange energy between main batteries (200-300V) and the drive motor with 500V dc link. High efficiency, lightweight, compact size and high reliability are some important requirements for the BDC used in such an application. Another, in a line-interactive UPS, the UPS output terminals are connected to the grid and therefore energy can be fed back to the inverter dc bus and charge the batteries via a BDC during normal mode. In backup mode, the battery needs the inverter dc bus again via BDC but this converter must be reversed power flow direction. Therefore, based on the above advantage, a smart power supply system using the Non-Isolated Bidirectional Dc-Dc Converter (NBDC) is developed [10]-[14].

This paper deals with the grid interconnection independence power supply system construction and its smart circuit study. Then, the developments and evaluations of the most important IGBT semiconductor device gate-drive circuit and voltage-current detecting circuit of the control system are described in the circuit that makes up the system. Moreover, the comparison of voltage control mode in battery voltage range is considered for this smart system operating. In addition, the isolated power supplies effectiveness, the smart circuit developments and the experiment results of the PV-PCS interconnection isolated power system for stable supply with the existing residential Photovoltaic-Power Conditioning Subsystem (PVPCS) of Japan are investigated and discussed.

This paper can be divided into six parts. The first part discusses a brief introduction of the control unit development of smart residential PV-PCS power supply system connected battery storage using BDC. The second part describes about the outline of smart power supply system. The third part discusses the residential PV-PCS stable power supply delivery system configuration about non-isolated BDC (NBDC) fundamental control. The fourth part discusses about the residential PV-PCS power supply system development with self-supported power supply function. The fifth part discusses about the PV-PCS power supply system operation experiment with battery storage in isolated mode. Lastly, the sixth part summarizes the conclusion. 


\section{Outline of Smart Power Supply System Using Battery Storage and Residential PV-PCS}

As PV power generation greatly depends on weather conditions, the output has bad influences to the power system. On the other hand, it is known that the surplus power is generated at the light load time of the power system. This causes the increasing of voltage problem in the power distribution network [15], [16]. Recently, the power supply capacity in Japan is tight because of the cease of operations of nuclear power plants. If households can use the power independently from the power system, these loads can be detached voluntarily from the power system at the event of power shortage. Therefore, there is a flexible operation of reducing the load in the power system and uninterrupted power supply to the load during power outage [7], [9]. Effectiveness of smart power supply system using residential PV-PCS and battery storage with the grid-connected and self-sustainable power supply (isolated power supply function of residential PCS) is described as follows.

\subsection{Grid-connected model or isolated model}

- When households could use the power independently from the power system in case of power shortage, the power system load is reduced.

- When PV output fluctuation could be suppressed by the charging and discharging control of battery storage, the fluctuation can absorbs and stable power can supply to their load or the power system from a consumer side.

- When the reverse power flow of renewable energy is increased the distribution line voltage, battery storage system can avoid the distribution line voltage issue and can suppress PV output fluctuation.

\subsection{Emergency model}

- It is difficult to get the stable power from only PV system because the output of PV fluctuates with the amount of solar radiation. However, the proposed power system can supply the stable power to households and refuges by combining the proposed system with EV and lead battery.

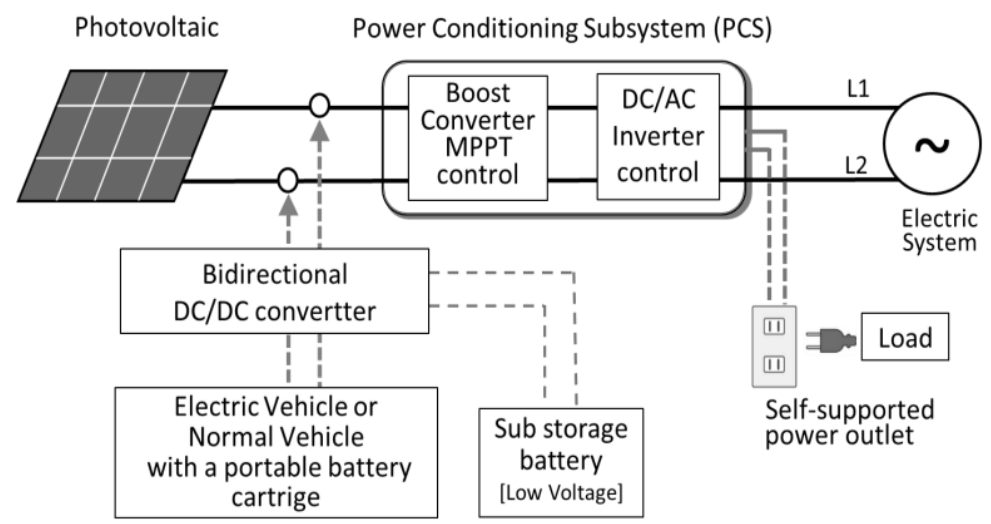

Fig. 1. Fundamental PV-PCS smart power supply system structure with self-supported power outlet.

\section{Smart Power Supply System Configuration Using Battery Storage and Residential PV-PCS}

\subsection{PV-PCS smart power supply system structure with self-supported power outlet}

In Fig. 1, it is shown smart power supply system configured with the existing residential Photovoltaic (PV) and Power Conditioning Subsystem (PCS). The commercial PV-PCS system in Japan is a product compliant to the power system interconnection guidelines with the reversing power flow function. Also, the existing residential PV-PCS is able to be grid interconnection to the power supply system constantly, and the proposed smart power supply system has a function of the isolated power supply on the power 
system cut-off. On the other hand, PV-PCS equipment can operate the solar energy power conversion, and it also has the advantage of non-polluting and noise less. However, it has the disadvantage of PV power fluctuation by weather changing. To suppress the PV power fluctuation, it is effective that use the construction of the PV power fluctuation suppressing control with connected the non-isolated bidirectional converter (NBDC) and lead battery or EV large-capacity battery to PV-PCS constant dc voltage bus, but in the existing residential PV-PCS is not installed the this connecting terminal. The proposed structure shown in Fig. 1 which has the important characteristics that it can be the output of the isolated power supply of the single phase $100 \mathrm{Vac} 1500 \mathrm{~W}$ with using the PCS self-supported power outlet in the power system cut-off.

\subsection{Non-isolated bidirectional dc-dc converter (NBDC) topology}

Fig. 2 shows the non-isolated bidirectional dc-dc converter (NBDC) topology including bidirectional converter structure and the theoretical operating waveform. NBDC structure shows in Fig. 2 (a) which is standard buck-boost converter. $V_{P V}$ is the dc voltage of high voltage side $(\mathrm{HV})$, and $V_{\text {batt }}$ is the dc voltage of low voltage side (LV). $i$ is the discharge dc current which flows from $V_{\text {batt }}$ to $V_{P V}$. Where $T=1 / f_{s w}$ is the switching period and $D$ is the NBDC control duty-cycle. Fig. 2 (b) depicts the theoretical operating waveform of buck-boost converter with S1 and S2 of IGBT semiconductor module. Table 1 is shown the system operating mode in DC voltage regulation. PV array uses in this research which is installed at laboratory building of Kyushu Institute of Technology (Kyutech). There are sixteen cells in this array in which one cell has a maximum voltage of $23.6 \mathrm{~V}$ and minimum current of 7.36A. Eight cells are arranged in series and there are two columns in parallel. The PV array capacity under study is $2.88 \mathrm{~kW}$. This capacity will be assumed as the residential use. As a dc voltage investigation result of Table.1, there are various types in the major EV (PHV) and lead battery of Japan. With regard to the EV battery voltage, $72 \mathrm{~V}$ of COMS battery voltage is the smallest while the $360 \mathrm{~V}$ of LEAF battery voltage is the largest. Therefore, a circuit configuration which is able to be connected in these dc battery voltage ranges has to be considered by each regulation modes of Table 1 .

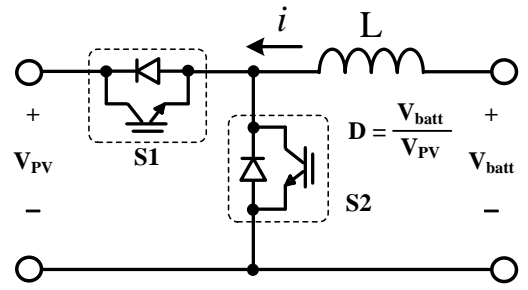

(a)

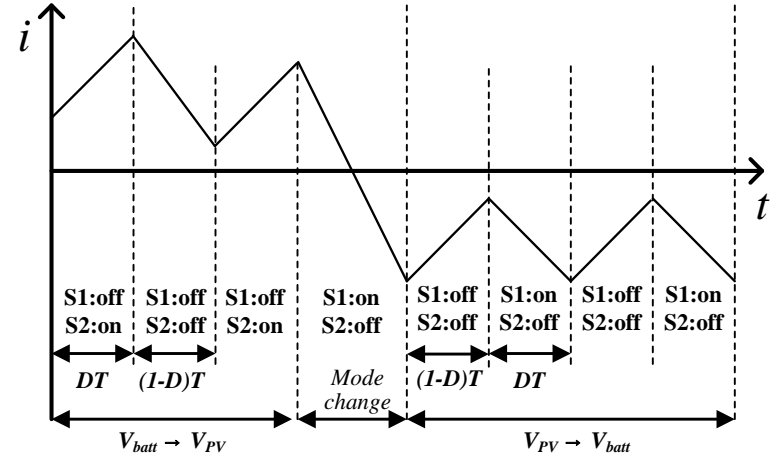

(b)

Fig. 2. NBDC topology: (a) NBDC structure, (b) theoretical operating waveform.

Table 1. System operating mode in DC voltage regulation

\begin{tabular}{|c|c|c|c|}
\hline & Vpv & PV-PCS volta & ge in Kyutech \\
\hline Vbatt & & $60[v]$ & $188[v]$ \\
\hline $\begin{array}{c}\text { Lead } \\
\text { Battery }\end{array}$ & $\begin{array}{l}12[v] \\
24[v]\end{array}$ & \multicolumn{2}{|c|}{ Vpv > Vbatt } \\
\hline COMS & $72[v]$ & Vpv $<$ Vbatt & Vpv > Vbatt \\
\hline $\begin{array}{c}\text { PRIUS } \\
\text { i-MiEV } \\
\text { LEAF }\end{array}$ & $\begin{array}{l}207[v] \\
330[v] \\
360[v]\end{array}$ & \multicolumn{2}{|c|}{ Vpv $<$ Vbatt } \\
\hline
\end{tabular}




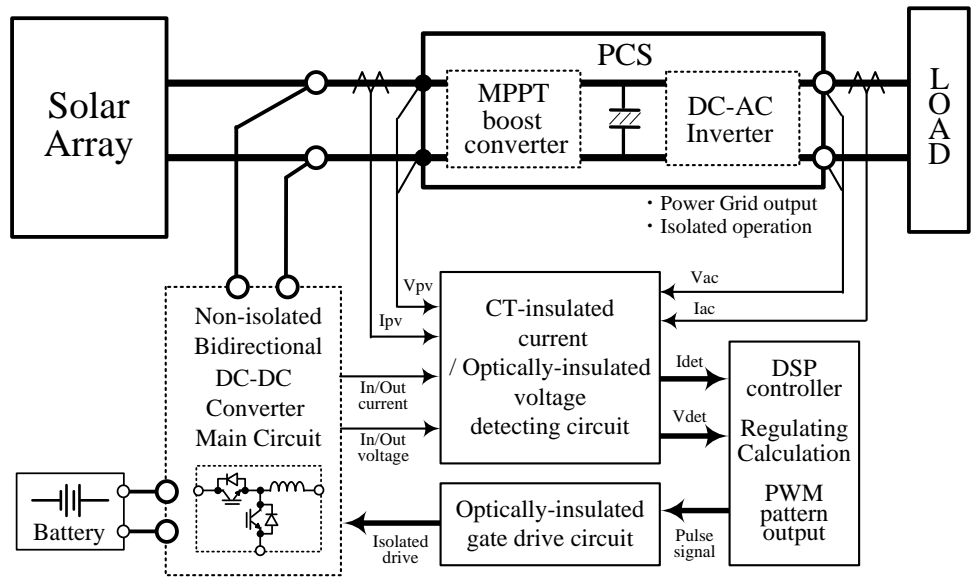

Fig. 3. Control block diagram using the residential PV-PCS with self-supported power supply function.

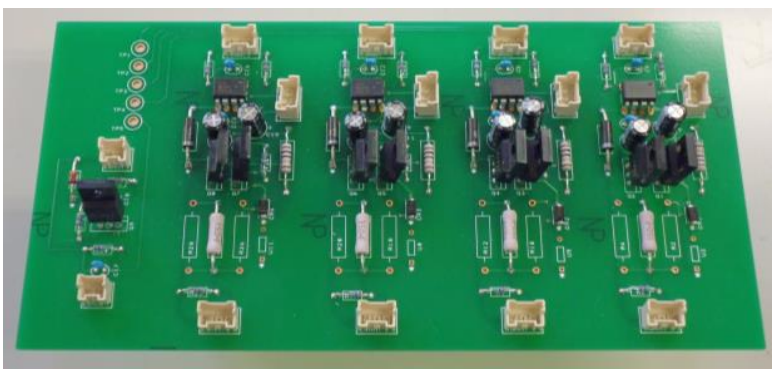

(a)

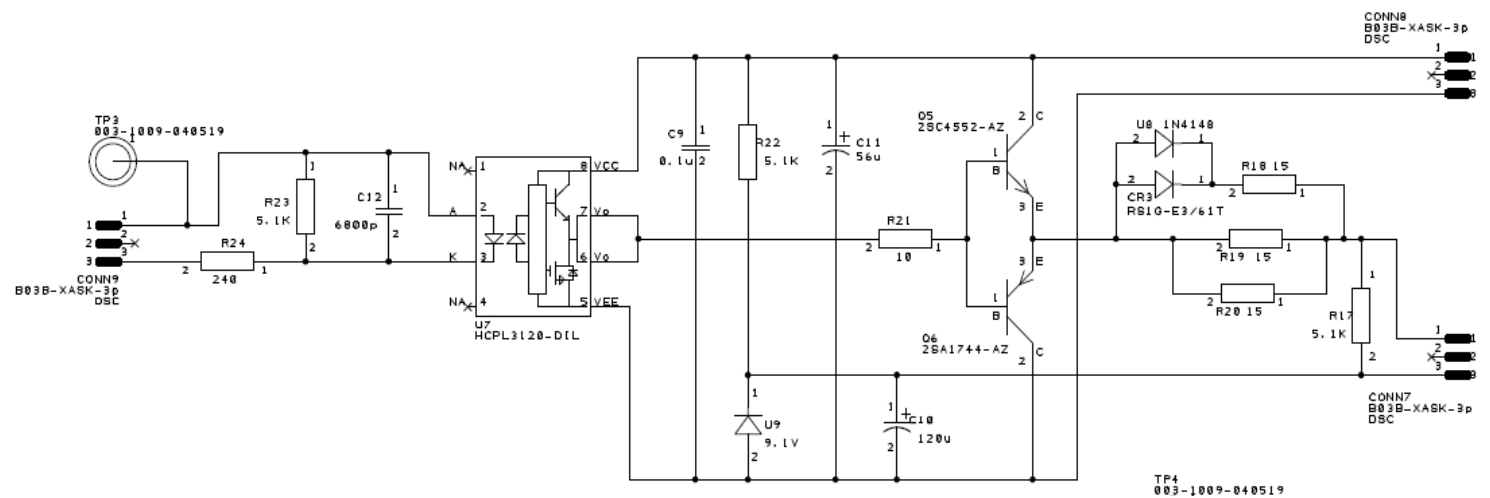

(b)

Fig. 4. Development of smart gate drive circuit: (a) Gate drive circuit board, (b) schematic diagram.

\section{Control Unit Development for Smart Power Supply System}

\subsection{Control system and circuit board development}

From Fig. 3, it demonstrates the control block diagram using the residential PV-PCS with selfsupported power supply function. Based on Fig. 3, the developed system is constructed with PV, PCS, NBDC including Insulation power supply, Battery, Optically-insulated gate drive circuit for IGBT semiconductor module, and CT-insulated current/Optically-insulated voltage detecting circuit. DSP controller operates the duty regulation using the detected current/voltage in unit's primary/secondary side, and it outputs the PWM pattern according to the developed control algorithm as pulse signal. For 
Optically-insulated gate drive, HCPL3120 photo-coupler gate drive IC is used. In Fig. 4, it shows its Gate drive circuit board and schematic diagram. For Optically-insulated voltage detection, HCPL7800 photocoupler insulation AMP is used. From Fig. 5, it displays its Voltage-Current (VI) detecting circuit board and Voltage detecting schematic diagram. Their circuits were able to design $10 \mathrm{~cm}$ x $20 \mathrm{~cm}$ small size boards as shown in Fig. 4 and Fig. 5.

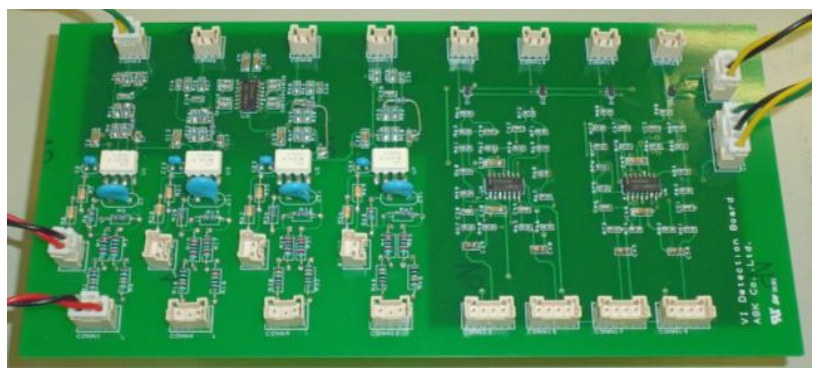

(a)

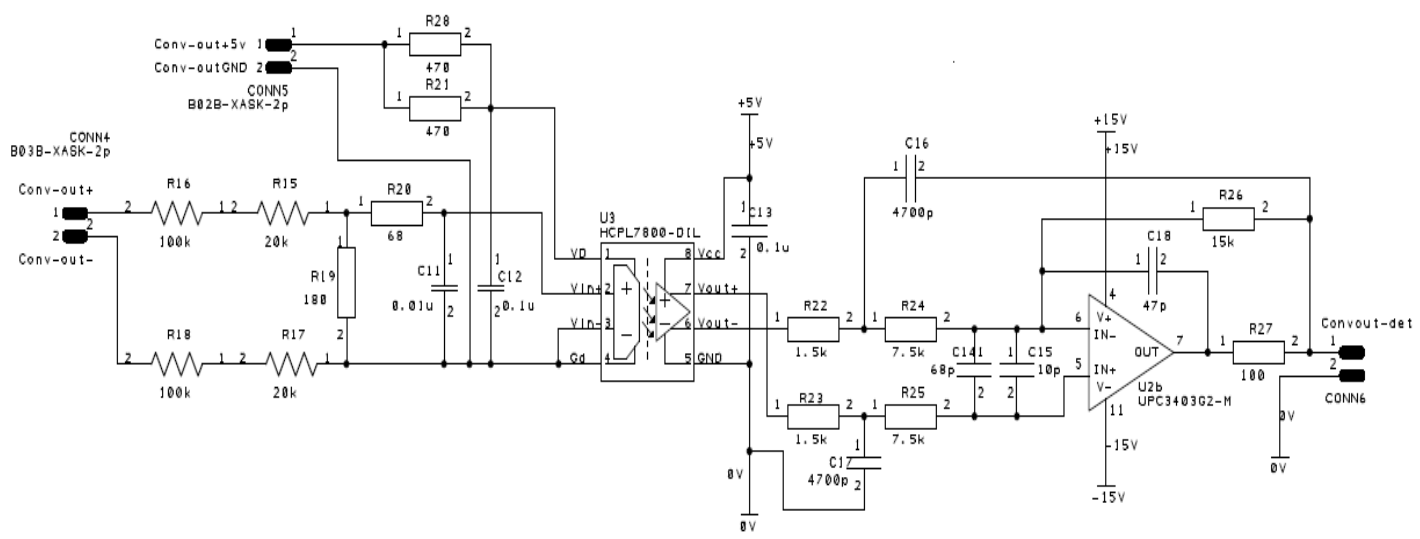

(b)

Fig. 5. Development of smart detecting circuit: (a) VI circuit board, (b) voltage detecting schematic diagram.

\subsection{Evaluation of the insulation voltage detecting circuit}

In the photo-coupler insulation IC (HCPL7800) of the optically-insulated voltage detecting circuit, for their evaluation, the equations of voltage transforming gain and voltage detection error are shown as the following; $G_{I N}$ is High voltage transforming gain [180/(240k+180)]. $G_{H C P L 7800}$ is IC transforming gain and its value is $8 . G_{V d e t}$ is the AMP IC designed gain on low voltage [15k/(1.5k+7.5k)]. Therefore, $G_{\text {Vout }}$ gain of the approximate 100 is calculated by the equation (1). To evaluate the developed board, it is necessary to calculate the error of the equation (2) with used the measurement. Table 2 and Fig. 6 are shown the evaluation result of isolated voltage detecting circuit. The results of table 2 were shown that the error is within $1 \%$. However, the input voltage detection of more than $100 \mathrm{~V}$ was the error $<1 \%$ from Fig. 6 . So, the error of less than $100 \mathrm{~V}$ was in a range of $\geq 1 \%$ and $<10 \%$. Where, $V_{I N}$ is the input DC high voltage, $V_{\text {det }}$ is the detected DC voltage of the converter circuit in low voltage. Since the insulating current is detected by the all elements CT, isolated circuit is unnecessary. Addition, two step filter circuit for removing the detected white noise is configured to the current detection circuit. The voltage detecting circuit is a circuit important element in this study. The voltage detecting circuit is performed by a controllable low voltage from the high voltage. In order to avoid complication of the circuits, HCPL7800 device of the optically-insulated voltage converter is applied. Thus, without constituting a complicated the multistage AMP circuits, it can be advantageously insulated from the high voltage part. However, because of a detection accuracy error in each device, the accuracy evaluation is required after the configuration of the circuit. For example, when there is the detection error $5 \%$ in $300 \mathrm{~V}$ for dc input voltage, $15 \mathrm{Vdc}$ steady- 
state error voltage is generated in the voltage regulation.

$$
\begin{aligned}
& G_{\text {Vout }}=G_{I N} \times G_{H C P L 7800} \times G_{V d e t} \\
& \text { error }[\%]=\left(V_{\text {in }}[v]-\frac{V_{\text {Vdet }}[v]}{G_{\text {Vout }}}\right) \div V_{\text {in }}[v] \times 100
\end{aligned}
$$

\begin{tabular}{|c|c|c|c|c|c|c|c|c|c|c|c|c|}
\hline & \multicolumn{3}{|c|}{ Ch1 } & \multicolumn{3}{|c|}{ Ch2 } & \multicolumn{3}{|c|}{ Ch3 } & \multicolumn{3}{|c|}{ Ch4 } \\
\hline $\operatorname{Vin}[v]$ & 300.07 & 200.04 & 100.02 & 300.07 & 200.00 & 100.06 & 300.02 & 200.03 & 100.02 & 300.05 & 200.02 & 100.05 \\
\hline Vdet [v] & 2.9818 & 1.9890 & 0.9949 & 2.9816 & 1.9907 & 0.9997 & 3.0213 & 2.0180 & 1.0132 & 3.0115 & 2.0109 & 1.0096 \\
\hline Error [\%] & 0.63 & 0.57 & 0.53 & 0.64 & 0.47 & 0.09 & -0.70 & -0.88 & -1.30 & -0.37 & -0.53 & -0.91 \\
\hline
\end{tabular}

Table 2. Evaluation of isolated voltage detecting circuit

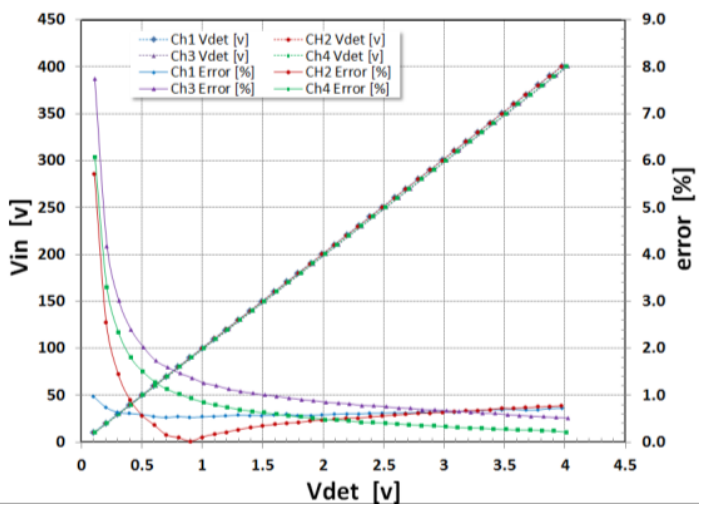

Fig. 6. Measurement result of isolated voltage detecting circuit.

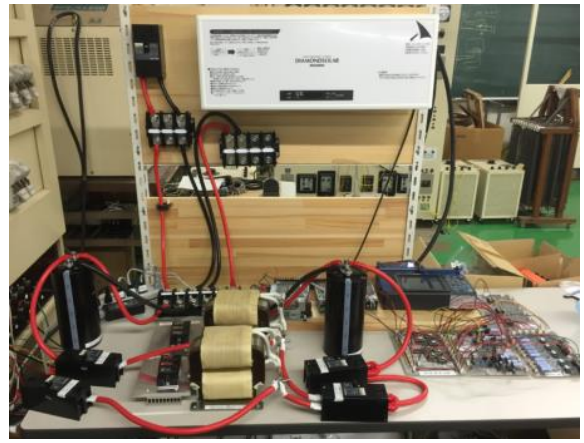

(a)

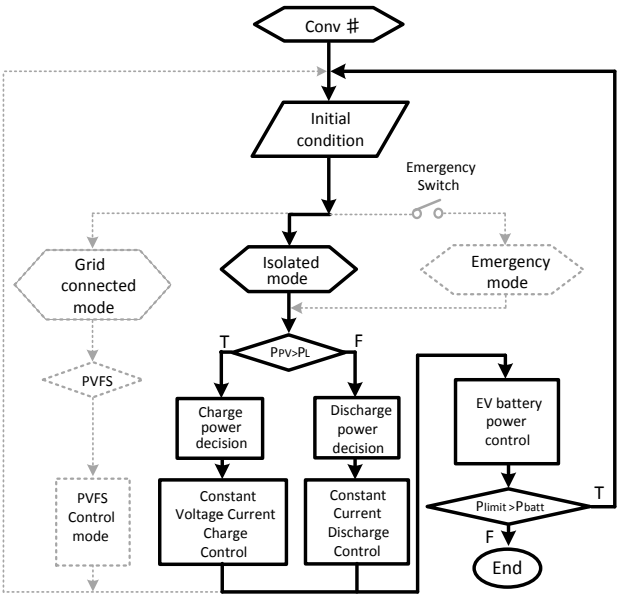

(b)

Fig. 7. Smart power supply system using self-supported power outlet: (a) experiment unit, (b) isolated control mode

\section{Experiment of Smart Power Supply System in an Isolated Control Mode}

\subsection{Isolated power supply experiment unit and control mode}

In Fig. 7, it is shown the experiment unit and isolated control mode of smart power supply system 
using self-supported power outlet. Based on Fig. 7(a), it is used PCS unit of the manufacturing Mitsubishi Electric Corporation. Moreover, the unit control algorithm of isolated power supply mode is shown in Fig. 7 (b) for the experiment. It has 2 modes of "Battery discharging mode" and "PV charging mode" on the isolated power supply system using NBDC.

\subsection{Battery discharging and PV charging control experiment using NBDC}

Based on Fig. 8, it depicts the isolated power supply discharging experiment results in PCS-NBDC with $72 \mathrm{~V}$ battery. Additionally, it shows the experiment structure of the $72 \mathrm{~V}$ battery discharging operation with used the PCS and NBDC. Pconvpv is NBDC output power. Pconvev is $72 \mathrm{~V}$ battery output power (NBDC input power). Ppcsin is PCS input power. Ppcsout is PCS output power (for Load power). Where, in Fig. 8(a), Iconvpv is NBDC output current, Iconvev is $72 \mathrm{~V}$ battery output current (NBDC input current), Vconvpv is NBDC output voltage, and Vconvev is $72 \mathrm{~V}$ battery output voltage (NBDC input voltage). Fig. 8(b) shows the experiment result of power factor $100 \%$ for loads. Loads are 80, 170, 260, and $320 \mathrm{~W}$ respectively.

In Fig. 9, it shows the isolated power supply charging experiment results of PV-NBDC with 72V battery. In fact, Fig. 9 demonstrates the experiment structure of the $72 \mathrm{~V}$ battery charging operation with used PCS and NBDC. Pconvpv, Pconvev, Iconvpv, Iconvev, Vconvpv, Vconvev are the same as Fig. 8(a). In Fig. 9(b) shows the result of battery charging (Buck operation On/Off) experiment, where solar array open voltage is $236 \mathrm{~V}$ and its maximum power voltage is approximately $188 \mathrm{~V}$ and its maximum power current is approximately $15 \mathrm{~A}$. If PV generates maximum power, $\mathrm{PV}$ output voltage $188 \mathrm{~V}$ is maintaining when battery changing current is less than maximum power current $15 \mathrm{~A}$. Therefore, it can be seen from Fig. 9(b) that the charging power to Battery is approximately $1000 \mathrm{~W}$.

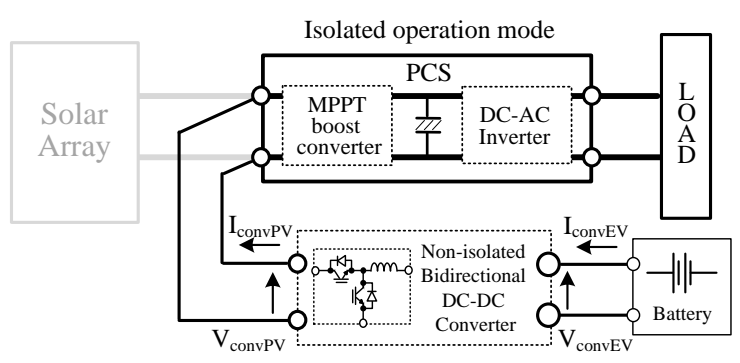

(a)

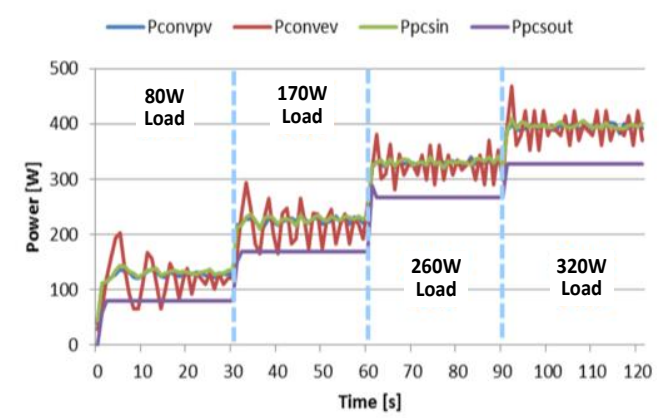

(b)

Fig. 8. Isolated power supply discharging experiment of PCS-NBDC with $72 \mathrm{~V}$ battery: (a) experiment structure, (b) power results.

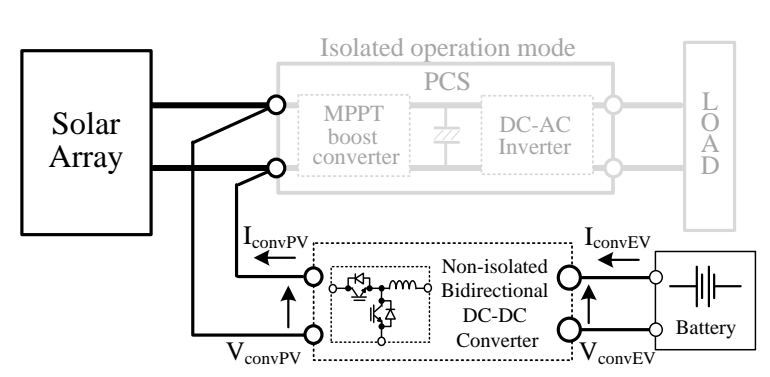

(a)

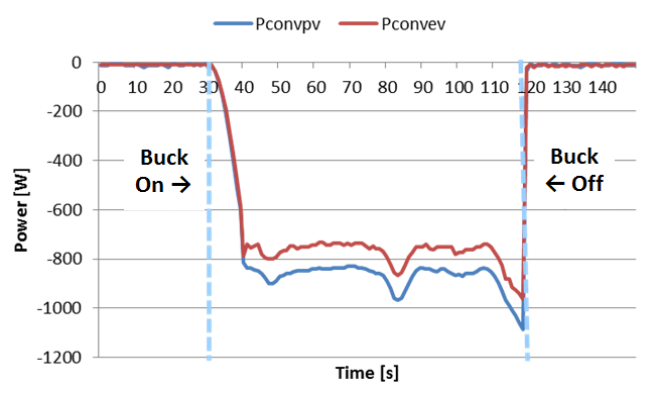

(b)

Fig. 9. Isolated power supply charging experiment of PV-NBDC with 72V battery: (a) experiment structure, (b) power results. 